\title{
A constituição que não foi: projetos derrotados para a segurança pública na Nova República
}

Pedro Benetti

\author{
Pedro Benetti \\ Bacharel em Relações Internacionais pela Pontifícia Universidade \\ Católica do Rio de Janeiro, mestre em Ciência Política pelo \\ Instituto de Estudos Sociais e Políticos IESP-UERJ e doutor pela \\ mesma instituição. Atualmente é trabalha como professor \\ pesquisador da Universidade de São Paulo. \\ E-mail: pedrorolobenetti@gmail.com \\ ORCID: http://orcid.org/0000-0003-1396-8654
}

\begin{abstract}
Resumo
A proposta do presente texto consiste em recuperar as propostas para a organização das forças repressivas do Estado derrotadas no contexto dos debates em torno da constituinte de 1987-8. Isso será realizado por meio da pesquisa de documentos publicados por diferentes atores sociais do período, bem como das menções constantes nos debates registrados nos anais da Assembleia Nacional Constituinte (ANC), disponíveis no acervo do Senado Federal. Ao recuperar esta documentação pretendo (1) demonstrar que a reprodução do modelo de segurança pública legado da ditadura militar (1964-1985) foi resultado de trabalho ativo de forças sociais organizadas politicamente para afastar as propostas renovadoras formuladas em diferentes espaços da sociedade brasileira; (2) ao demonstrar o sentido de disputa envolvido na conformação do atual sistema, desnaturalizar sua forma presente e ressaltar a possibilidade/necessidade de que seja debatido, repensado e reformulado e; (3) recuperar, na história dos projetos derrotados, propostas que sigam pertinentes à realidade brasileira e que possam lançar luz sobre alternativas para enfrentar a crise de segurança que há tantos anos nos aflige.
\end{abstract}

\section{Palavras-chave}

Segurança Pública, Forças Armadas, Constituição, Transição.

\begin{abstract}
The purpose of this text is to recover the proposals for the organization of the repressive forces of the State defeated in the context of the debates around the 19878 constituent. This will be done through the search for documents published by different social actors of the period, as well as the mention in the debates registered in the annals of the National Constituent Assembly (ANC), available in the collection of the Federal Senate. In retrieving this documentation, I intend to (1) demonstrate that the reproduction of the public security model inherited from the military dictatorship (1964-1985) was the result of the active work of politically organized social forces to ward off the renovating proposals formulated in different spaces of Brazilian society;

(2) by demonstrating the sense of dispute involved in shaping the current system,
\end{abstract}


Pedro Benetti

denaturalizing its present form and highlighting the possibility / need for it to be debated, rethought and reformulated and; (3) recover, in the history of defeated projects, proposals that remain relevant to the Brazilian reality and that can shed light on alternatives to face the security crisis that has afflicted us for so many years.

\title{
Key words
}

Public Security, Armed Forces, Constitution, Transition.

\section{Introdução}

\author{
A reflexão leva a um beco sem saída? É óbvio que não. \\ Pela primeira vez em nossa história, Constituição, \\ Democracia e Revolução aparecem como entidades \\ históricas em relação de interdependência e de \\ reciprocidade. (FLORESTAN FERNANDES, Constituição e \\ revolução)
}

Publicado em janeiro de 1986 na Folha de São Paulo, o artigo de Florestan Fernandes que abriga a passagem trazida acima é exemplar da percepção compartilhada entre diversos intelectuais e atores políticos da década de 1980 acerca da abertura que aquele período oferecia para a disputa entre diferentes projetos de sociedade e a possível aceleração de processos de transformação do país que até então tinham andado em marcha lenta. Sem deixar de reconhecer o peso do passado recente, bem como das longas estruturas que formaram a sociedade e o Estado no Brasil, Fernandes e outros entenderam que o momento de transição era uma fenda na história. Se Tancredo Neves chegara a definir o período como marcado por crises simultâneas (política, econômica e social), os textos de intelectuais, políticos e ativistas revelam também um tom de esperança no que poderia ser construído.

Este espírito contrasta com os diagnósticos contemporâneos de cientistas sociais acerca da incompletude de nossa democracia. Em linhas gerais, acusa-se a insuficiência da transição em superar as estruturas autoritárias, substituindo-as adequadamente por instituições democráticas em seu desenho e funcionamento. Transição pelo alto, negociada, incompleta, débil, incapaz de superar os entulhos autoritários foram algumas das expressões correntes no debate público sobre o tema ${ }^{1}$. O caso exemplar dessa inércia autoritária seria o da segurança pública, cujo modelo reproduziria, em grande medida, o legado da ditadura militar. Frente a uma recente onda de estudos ${ }^{2}$ que mapeiam as continuidades autoritárias observáveis no presente, a ressalva de Luiz Eduardo Soares em relação à maneira como olhamos para o passado imediato pode servir como um chamado para que se encontre uma boa medida entre elementos que teríamos "recebido" da última ditadura e traços mais permanentes de nossa formação social que funda sua noção de ordem no emprego continuado da violência.

Observe-se aqui um ponto relevante: a ditadura não inventou a tortura e as execuções extrajudiciais ou a ideia de que vivemos uma guerra contra inimigos internos. Tais práticas perversas e as correspondentes concepções, racistas e autoritárias, têm a idade das instituições policiais no Brasil e, até mesmo antes de sua criação, já 
Pedro Benetti

tinham curso. A ditadura militar e civil de 1964 simplesmente reorganizou os aparatos policiais, intensificou sua tradicional violência, autorizando-a e a adestrando, e expandiu o espectro de sua abrangência, que passou a incluir militantes de classe média. Ainda assim, foi esse regime que instituiu o modelo atualmente em vigência. (SOARES, 2015, p.25)

A esperança de que o processo de democratização política em curso nos anos 1980 produzisse efeitos sobre as formas de exercício da violência por parte do Estado pode ter causado perplexidade em atores políticos, sociais e pesquisadores, quando a realidade foi confirmando a reprodução dos padrões violentos verificados na ditadura e, pior do que isso, um crescimento em todos os indicadores relativos à violência estatal. Batista (2015) afirma que na saída da ditadura observava-se uma resistência à brutalidade policial na sociedade brasileira, mas esse panorama se converteu rapidamente na naturalização da truculência contra as parcelas mais pobres da população e daí ao seu aplauso. Ela identifica que, com enorme contribuição da mídia, o inimigo interno foi deslocado para o criminoso comum, particularmente os traficantes de drogas que operam no varejo, de perfil mais pobre. Assim, foi mantida a estrutura de controle social do período anterior e os níveis de autoritarismo foram aprofundados em certos aspectos (BATISTA, 2008).

A constatação de certas continuidades em relação ao período da última ditadura militar não deve, entretanto, ser tomada como sinal de inércia ou ausência de propostas alternativas.

\footnotetext{
Partimos do pressuposto de que não há "restos", como se fossem aspectos não superados de uma forma que foi suplantada e deixou atrás de si elementos ainda esperando por serem enfrentados. Há permanências somente no sentido de que tais aspectos seguem funcionais à ordem a qual se associam. (IASI, 2014, p. 81)
}

O que a passagem de Iasi busca salientar é a noção de que não existem enclaves esquecidos da antiga ordem na nova, mas sim elementos de continuidade que são constantemente produzidos, reproduzidos e atualizados. Nesse sentido, para que continuem ativas no novo arranjo, estas estruturas, por vezes tomadas como restos, precisaram disputar e derrotar outras perspectivas de organização do Estado brasileiro. O objetivo do presente texto consiste em recuperar as propostas para a organização das forças repressivas do Estado derrotadas no contexto dos debates em torno da constituinte de 1987-8. Isso será realizado por meio da pesquisa de documentos publicados por diferentes atores sociais do período, bem como das menções constantes nos debates registrados nos anais da Assembleia Nacional Constituinte (ANC), disponíveis no acervo do Senado Federal.

Ao recuperar esta documentação pretendo (1) demonstrar, por meio da recuperação das alternativas, que a reprodução do modelo de segurança pública legado da ditadura militar foi resultado de trabalho ativo de forças sociais organizadas politicamente para afastar as propostas renovadors formuladas em diferentes espaços da sociedade brasileira; (2) ao demonstrar o sentido de disputa envolvido na conformação do atual sistema, desnaturalizar sua forma presente e ressaltar a possibilidade/necessidade de que seja debatido, repensado e reformulado e (3) recuperar, na história dos projetos derrotados, propostas que sigam pertinentes à realidade brasileira e que possam lançar luz sobre alternativas para enfrentar a crise de segurança que há tantos anos nos aflige. Para cumprir os objetivos propostos, o artigo está subdividido em três tópicos, sendo um primeiro sobre os debates e interpretações 
Pedro Benetti

em torno da transição entre a última ditadura militar e a democracia; o segundo apresentando brevemente a estrutura da ANC e alguns dos pontos principais acerca da segurança pública na nova carta e; o terceiro trazendo as propostas derrotadas para a organização das forças repressivas do Estado no novo regime político.

\section{A transição para a democracia}

Embora seja comumente retratada como um exercício de vontade dos governantes no poder, a transição da ditadura militar para a democracia foi resultado também de um intenso esforço de mobilização de diversos setores sociais na crítica frontal ao autoritarismo. Greves, guerrilhas urbanas e rurais, campanhas internacionais de opinião e outros recursos foram empregados no esforço de deslegitimar a ditadura militar no Brasil. A escalada da repressão e o fortalecimento da chamada comunidade de informações ${ }^{3}$ produziu, progressivamente, uma repulsa da sociedade aos níveis de violência empregados pelo Estado.

Em 1974, quando Ernesto Geisel assume a presidência da república para o quarto mandato de um general ditador, as organizações armadas de enfrentamento ao regime militar já haviam sido derrotadas. Nesse momento, diversos atores sociais começavam a se reunir em torno da necessidade de redemocratizar o país. Jornais da imprensa alternativa como O Pasquim, Opinião e Movimento buscavam furar o bloqueio da censura para fazer circular um conjunto de críticas ao regime (KUCINSKI, 1991). Na academia formavam-se centros de estudos e publicações periódicas que também colocavam como tema central o retorno à democracia, como evidenciam os exemplos do Cebrap e, mais adiante, do Cedec (PERRUSO, 2009; PECAUT, 1990). Por outro lado, começava a surgir a hipótese de que muitos dos militares se preocupavam com o fortalecimento da comunidade de informações, que constituiria um poder paralelo dentro das forças armadas, subvertendo o princípio da hierarquia, estruturante de sua organização burocrática.

A ideia de que os militares se retiraram do poder para
preservar a unidade da corporação ocorreu a várias
pessoas. Segundo essa perspectiva, as Forças Armadas,
estando divididas politicamente, teriam diagnosticado que
a permanência no poder era a causa das divisões, pelas
ambições políticas que gerava, que acabavam superando
o tradicional espírito de unidade da corporação. Essa
teoria, se bem contribua para explicar o fim do regime,
encontra dificuldades em explicar por que o fim não se
deu antes, quando houve pesados enfrentamentos entre
diferentes correntes militares: primeiro, quando Costa e
Silva e um grupo de oficiais radicais impuseram a sua
candidatura, em detrimento de uma candidatura
politicamente mais aceitável; segundo, quando, na
sucessão de Costa e Silva, sem um líder que a
influenciasse, vários candidatos se apresentaram ou
foram apresentados (D'ARAUJO, CASTRO e SOARES,
1994, p. 30)

A preocupação com os efeitos que a repressão produziria para dentro das instituições militares pode ser um elemento que se soma aos demais citados na explicação do porquê a segunda metade dos anos 1970 assiste ao desenrolar de um processo de transição ${ }^{4}$. O anúncio de uma transição lenta, gradual e segura para a democracia, por parte de Geisel, revelava a pretensão de um processo controlado de reorganização institucional, que levaria os militares de volta aos quartéis e garantiria um modelo político suficientemente preparado para conter o que eles consideravam radicalismos de esquerda. Ao mesmo tempo, o ano de 1974 foi emblemático também para as oposições ao regime, na medida em que o avanço eleitoral do MDB abria o 
Pedro Benetti

debate acerca das possibilidades de derrotar o autoritarismo por dentro do sistema institucional por ele mesmo constituído. A partir de então, a dinâmica dos debates entre as diversas esquerdas existentes no Brasil esteve absorvida pela questão do posicionamento a ser adotado frente à estratégia de distensão que vinha de dentro do sistema político. Se até então a luta se concentrava em grupos que estavam longe dos círculos do poder, agora a discussão passava pela aceitação ou não da política de abertura do governo e dos canais de representação da oposição (principalmente o MDB).

Contabilizados os votos, a surpresa foi geral: o partido de oposição, MDB, consegue 16 das 22 cadeiras de senadores em disputa, além de aumentar de $28 \%$ para $44 \%$ sua bancada na Câmara. Nas eleições majoritárias, 0 MDB também aparece como vencedor nos 16 estados. Percebendo as possibilidades reais de crescimento e fortalecimento através de eleições, a oposição se aproxima da estratégia militar, principalmente depois da vitória eleitoral alcançada em 1974. (CARVALHO, 2000, p. 377)

A ideia de que o país viveu um período de transição a partir de 1974 foi comum a atores sociais, políticos e analistas (LESSA, 1989; WERNECK, 1986; TEIXEIRA DA SILVA, 2000 e outros). Entretanto, os sentidos encontrados em meio ao emaranhado de eventos e mobilizações que ocorreram no período podem variar de acordo com as diversas perspectivas de análise. Embora a maior parte das leituras concorde que 0 elemento mais característico de processos de transição como o brasileiro é a incerteza, esquemas explicativos como o de O'Donnell e Schmitter (1988) reservam espaço reduzido para o protagonismo de atores que não se engajassem diretamente na relação (mesmo que crítica) com os grupos que ocupavam o Estado. A transitologia, campo de estudos que derivou dos trabalhos fundadores de O'Donnell e Schmitter, tendeu a observar com maior cuidado as divergências existentes no interior dos blocos de poder - através de categorias como brandos e duros, opositores minimalistas e maximalistas - e os impulsos liberalizantes ou democratizantes que predominavam em cada processo - adaptando categorias formuladas por Robert Dahl (1971) em "Poliarquia".

Esse modelo de explicação, quando aplicado ao Brasil, dedicou enorme atenção às tensões entre militares castelistas e linha-duras, às reformas que foram produzidas no interior do sistema político e ao avanço da organização das oposições que optaram pela via institucional.

A distensão proposta pelo presidente Geisel incluía várias medidas de liberalização, mas a redemocratização que o país experimentou foi além, em extensão e rapidez, da preconizada pelos seus mentores. Esta diferenciação entre liberalização e democratização é importante e, neste sentido, a contribuição de O'Donnell e Schmitter é fundamental. Liberalização seria a proteção de indivíduos e grupos contra o arbítrio do Estado ou de outros grupos. Como dizem aqueles autores, no nível individual, essas garantias incluem os elementos clássicos da tradição liberal: o habeas-corpus; a inviolabilidade residencial e da correspondência; o direito de defesa num tribunal justo e imparcial, de acordo com leis pré-estabelecidas; as liberdades de imprensa, de expressão, de petição, de associação e assim por diante. No nível grupal, esses direitos cobrem ainda garantias como as de que não haverá punição contra expressões de dissídio e dissensão 
Pedro Benetti

coletivos em relação a políticas governamentais. A democratização mais elementar, por sua vez, implica a possibilidade real de transferência de poder. (D'ARAUJO, CASTRO e SOARES, 1994, p. 13)

Menor ênfase recai sobre mobilizações que se dão na base da sociedade, como as greves do ABC paulista em 1978, os movimentos contra o aumento do custo de vida, também no fim dos anos 1970 , e as caravanas pela anistia, que buscavam trazer para o centro do debate público o tema dos perseguidos políticos. Ao longo de todo o processo de transição, os esforços do governo (tanto Geisel quanto Figueiredo, posteriormente) se encaminharam no sentido de isolar estas mobilizações e escolher os interlocutores com os quais dialogariam. Paralelamente, tais governos seguiram utilizando os instrumentos construídos no auge do autoritarismo para tentar controlar o espaço político dentro do qual operariam. Bons exemplos destas práticas foram a edição do Pacote de Abril, em 1977, pelo ministro Armando Falcão - quando o Congresso foi fechado a aprovou-se um conjunto de restrições à atuação da oposição consentida - e continuidade de operações repressivas contra comunistas, como a Chacina da Lapa5 ${ }^{5}$ em 1976, ou a Operação Radar, desencadeada a partir de 1974 com o objetivo de executar e desaparecer com os corpos de integrantes do comitê central do Partido Comunista Brasileiro (PCB) ${ }^{6}$.

A estratégia de transição que se desenha a partir de então - tanto por parte do governo autoritário quanto de setores da oposição - privilegia o Congresso como ambiente de tomada de decisões e articulação política entre governo e oposição. Ao contrário de países como Portugal, Grécia e Argentina, o Brasil não vivencia uma ruptura no momento de transição do regime autoritário para a democracia (LESSA, 1989). Aqui, a passagem se dá através das negociações estabelecidas entre os chamados incumbentes do regime e as oposições consentidas, cujos quadros representados no legislativo variavam de acordo com as novas regras impostas pelo regime. Em outras palavras, o Congresso foi escolhido pelo regime como seu interlocutor para a condução do processo de abertura, mas a própria composição deste Congresso variou na década de 1970 em função das medidas político-institucionais levadas adiante pelo governo. Os destinos do processo de transição estiveram em disputa no decorrer da década de 1980, o que era reconhecido pelos próprios analistas do período:

\footnotetext{
É ingênuo imaginar que a transição se limite a uma mera atualização das instituições jurídico-políticas a uma economia modernizada. Longe disto, ela significa o campo de disputa sobre se teremos ou não uma reordenação democrática das relações entre Estado e sociedade civil e a incorporação de novos setores sociais a uma livre e plena cidadania política, econômica e social. (...) A transição se conclui em favor da democracia, ou não. Ela pode-se perverter numa auto-reforma do antigo regime, ainda vivo nas instituições, no próprio governo e, principalmente, no sistema de poder. (WERNECK VIANNA, 1986, p. 23)
}

O diagnóstico de Werneck era o de que a realização de um processo de reforma institucional não representava necessariamente a superação do autoritarismo, na medida em que a transformação das instituições do país poderia se restringir a uma questão de forma, deixando em segundo plano o conteúdo das práticas e arranjos consagrados na modernização conservadora do Brasil. Numa transição como a brasileira, fortemente marcada pela presença dos incumbentes autoritários na mesa de 
Pedro Benetti

negociações, o risco de uma mera atualização de um regime restritivo à cidadania estava colocado. Nos países que encontraram sua via de transição através de uma ruptura com o regime anterior, o autoritarismo constituía um "outro político", com o qual era necessário romper para construir algo novo.

No caso brasileiro, por sua vez, quase todos os políticos encarregados da transição - mesmo os opositores - haviam construído seu patrimônio político no período do regime civil-militar de 1964, no âmbito das instituições representativas que mantiveram seu funcionamento. $O$ formalismo da coalizão conservadora que assumiu o controle do país após o golpe de abril de 1964 foi responsável pela manutenção de instituições compatíveis com o Estado de direito e a democracia - embora seu funcionamento fosse restrito. Estas instituições foram protagonistas na primeira etapa do processo de transição no Brasil. Segundo Lessa (1989), entre 1974 e 1982 houve predominância de elementos endógenos na transição brasileira, com pouco espaço para que as pressões que se articulavam na sociedade penetrassem o núcleo de poder. Nesse período, vários itens da agenda de mudança democrática foram avançados pelo governo, o que determinou uma feição conservadora a processos como a Lei de Anistia, o fim da censura e a devolução de algumas prerrogativas ao legislativo. Ao empreender reformas democratizantes, o governo autoritário se tornou co-patrocinador da ordem que emergiria em seu lugar, uma situação sem paralelo em outros processos de transição - mesmo os negociados, como o espanhol.

A partir de 1982, as oposições começam a assumir postos centrais na burocracia, ao sagrarem-se vencedoras das eleições diretas para os governos estaduais das regiões mais importantes política e economicamente do país. Daí em diante, o governo perdeu o controle absoluto sobre os rumos do processo de transição, obrigado a uma relação menos desigual com as forças oposicionistas. No entanto, o poder de veto sobre determinadas agendas democráticas manteve-se ao longo de todo 0 período.

Parece razoável estabelecer que entre 1974 e 1982 houve na abertura brasileira o predomínio de fatores endógenos. Porém, das eleições de 1982 em diante, as elites autoritárias conservaram apenas seu poder de veto em relação às demandas mais ousadas e urgentes. (LESSA, 1989, p. 91)

Esse poder de veto e a presença das elites do regime autoritário na dinâmica da transição são elementos fundamentais para a compreensão do objeto central deste texto. Afinal, foi justamente esse capital político o responsável pela continuidade das estruturas do sistema de segurança pública na passagem do regime autoritário para o democrático. Apesar das pressões vindas de fora do sistema político constituído, através de intensas mobilizações populares - cuja expressão máxima foi o movimento das Diretas Já! -, o bloco no poder conseguiu preservar posições que o tornassem ator incontornável na construção da nova ordem. Isso não significa que o processo de transição teve uma direção unívoca e absolutamente controlada de cima, mas que as forças sociais que se posicionaram criticamente ao regime militar ao longo de muitos anos não tiveram controle do processo. No mínimo, elas tiveram que se organizar numa relação direta com o funcionamento das instituições construídas na etapa anterior. Se a transição e seu símbolo maior, a Constituição, representam momentos de criação, no caso brasileiro os limites do impulso criador foram dados pela necessidade de enfrentar um regime que não estava completamente derrotado.

Esse modelo de substituição do regime autoritário foi consagrado com a decisão de fazer uma constituinte não-exclusiva, ou seja, uma assembleia constituinte composta pelos parlamentares eleitos nos últimos dois pleitos (1982 e 1986) - o que contrariou a maior parte das forças oposicionistas no país. Assim sendo, a Carta de 1988 nasceu dos trabalhos de duas legislaturas escolhidas ainda sob as regras eleitorais estabelecidas pelo governo militar. Embora 
Pedro Benetti

as eleições legislativas de 1986 tenham renovado parte significativa do Congresso, alguns dos parlamentares foram escolhidos ainda em 1982.

\begin{abstract}
A dinâmica responsável pela queda do regime militar e o advento do poder civil implicou de imediato a revitalização de centros de decisão alternativos frente a um poder executivo superdimensionado. O principal núcleo de poder criado foi o Congresso constituinte, encarregado de redefinir a ordem jurídico-institucional. Visto pela sociedade civil como espaço privilegiado de mudança, deslocou-se para o Congresso enorme parcela de responsabilidade na definição do pacto social e político que as forças condutoras da transição foram incapazes de articular. No entanto, o desempenho do Congresso constituinte esbarrou em dificuldades diversas. Um primeiro obstáculo adveio da superposição de funções legislativas ordinárias com funções constitucionais de caráter excepcional, em função da fórmula conservadora vitoriosa da constituinte congressual. Esta foi uma decisão estratégica das forças conservadoras da coalizão de poder e do próprio governo para garantir não só fortes linhas de continuidade com o regime anterior como o controle sobre a constituinte. (CAMARGO \& DINIZ, 1989, p. 12)
\end{abstract}

A constituinte foi palco de disputas acirradas entre impulsos democratizantes levados a cabo por forças progressistas e esforços continuístas empreendidos por políticos bem posicionados na antiga ordem. Assim como o conjunto do processo de transição, não se pode afirmar que ela foi totalmente controlada pelo regime, mesmo porque ocorreu já sob o governo civil de José Sarney. Se a marca das transições é a incerteza isso se deve ao fato de que diversos atores políticos estão engajados em uma disputa cujos desfechos podem seguir direções muito diversas. Na constituinte essa lógica também existiu, em certa medida. Por mais que houvesse expressiva maioria conservadora no colégio que produziu a nova carta, a articulação de atores da sociedade civil impôs intensa pressão sobre o processo de produção do novo texto. Ao mesmo tempo, políticos progressistas se articularam de maneira a ocupar o maior número possível de postos decisórios.

Os resultados tanto da transição como um todo quanto da constituinte são objeto de avaliações diversas e polêmicas até o presente momento. Isso não significa que as mudanças ocorridas na sociedade e na política brasileiras desde os anos 1980 tenham sido apenas aparentes. Significa sim que o processo de transição e seu símbolo maior, a constituição de 1988, são eivados de contradições e direções múltiplas, oscilando entre temas onde os setores progressistas foram capazes de avançar mais e outros nos quais o bloco de poder do regime anterior e a cultura política que se configurou nos anos 1980 foram capazes de encontrar os caminhos para a reprodução e perpetuação de suas lógicas. Essa tensão, estruturante dos trabalhos na ANC, será objeto do próximo tópico.

\title{
2. A constituinte 1987-8
}

O processo constituinte de 1987-8 foi um marco na superação do regime autoritário inaugurado em 1964. Convocada pelo presidente José Sarney em 1985, por meio da emenda $n^{\circ} 26^{7}$, a Assembleia Nacional Constituinte (ANC) reuniu 
Pedro Benetti

unicameralmente os parlamentares eleitos para a Câmara dos Deputados, integralmente renovada nas eleições de novembro de 1986, e do Senado Federal, renovado apenas parcialmente no mesmo pleito. Vinte e três dos setenta e dois senadores foram eleitos ainda nas eleições de 1982, o que motivou questionamento do Partido dos Trabalhadores (PT) e do Partido Comunista Brasileiro (PCB) à mesa da ANC sobre a legitimidade da participação dos mesmos no processo constituinte. O formato da ANC, que combinava as atividades parlamentares e constituintes, bem como o processo de escolha dos membros, contrariou a posição de organizações da sociedade civil que protagonizaram a crítica à ditadura militar a partir de meados dos anos 1970, tais como a Ordem dos Advogados do Brasil (OAB), a Associação Brasileira de Imprensa (ABI) e a Conferência Nacional dos Bispos do Brasil (CNBB).

No total, 559 parlamentares desempenharam as funções de constituintes entre $1^{\circ}$ de fevereiro de 1987 e 5 de outubro de 1988. Destes, 306 eram do Partido do Movimento Democrático Brasileiro (PMDB), 132 do Partido da Frente Liberal (PFL), 38 do Partido Democrático Social (PDS), 26 do PDT, 18 do PTB, 16 do PT, 7 do Partido Liberal (PL), 6 do Partido Democrata Cristão (PDC), 3 do PCB, 3 do Partido Comunista do Brasil (PC do B), 2 do PSB, 1 do PMB e 1 do PSC. Em junho de 1988, 38 parlamentares do PMDB, liderados por Mario Covas, deixaram o partido para fundar o Partido da Social Democracia Brasileira (PSDB). Os partidos conservadores somavam 201 cadeiras, enquanto os progressistas não chegavam a 50 (PILATTI, 2008). O PMDB tinha diversas tendências, sendo majoritariamente conservador, embora com algumas expressivas figuras progressistas, como o líder da bancada até junho de 1988, Mario Covas. PCB, PC do B, PDT, PSB, PT e, mais adiante, PSDB atuaram na maior parte do tempo como um bloco parlamentar, o chamado bloco progressista, que contou ainda com a participação de uma ala minoritária do PMDB. Por outro lado, formou-se um bloco conservador composto por PDS, PFL, PTB, PDC, PL e pela ala conservadora do PMDB, que a partir de novembro de 1987 passaria a se autodenominar como "centrão". Segundo Pilatti, esse bloco representava a "autêntica expressão parlamentar do partido da ordem" (2008).

No campo da segurança, algumas mudanças foram alcançadas, embora a maior parte das forças armadas do Estado tenham mantido estrutura similar. A "comunidade de informações" foi desmantelada, mas as Forças Armadas e as polícias sofreram poucas alterações em sua organização e funcionamento. Essa continuidade tem forte relação com o poder de veto que as forças do antigo regime mantiveram na passagem para a nova ordem. Assim sendo, ainda que houvesse amplo debate na sociedade sobre a temática da violência e da segurança pública, poucas propostas inovadoras foram incorporadas à Constituição. A mobilização promovida por atores da sociedade civil como o Grupo Tortura Nunca Mais e a Comissão de Justiça e Paz, amparada pela Arquidiocese de São Paulo, manteve o tema do emprego de violência por parte do Estado em evidência ao longo dos anos 1980. Entretanto, isso não foi suficiente para que a extensão do processo de reforma do Estado, que acompanhou a constituinte de 1987-8, alcançasse as instituições responsáveis pelas graves violações aos direitos humanos no período anterior.

Jorge Zaverucha (2013) menciona a existência de uma série de acordos de bastidores entre os militares e as lideranças civis do processo de transição para que a extensão das transformações fosse regulada. Nesse sentido, ele fala na existência de um compromisso entre Tancredo Neves e o então ministro do Exército, general Walter Pires, para que o processo constituinte se desse pela via congressual e não através de uma assembleia exclusivamente constituinte. Zaverucha menciona também a existência de ameaças militares ao conjunto do processo, sempre que iniciativas de controle do 
poder militar começavam a avançar no âmbito da constituinte. Sobre as propostas de desmilitarização das polícias, por exemplo, Zaverucha afirma que "Ulysses [Guimarães] disse a [coronel Sebastião Ferreira] Chaves 'que já não podia mudar nada porque tinha um compromisso com o general Leonidas [Pires] ${ }^{\prime \prime \prime}\left(\right.$ ZAVERUCHA, 2013, p. 50) ${ }^{8}$. O autor menciona também a organização de um bem estruturado lobby militar sobre a constituinte, levado adiante por 13 oficiais superiores que foram incumbidos da tarefa de mediar os interesses corporativos de suas instituições com os parlamentares constituintes (ZAVERUCHA, 2013, p. 45) ${ }^{9}$. Durante os trabalhos da subcomissão ${ }^{10}$ que cuidou dos assuntos relacionados às instituições armadas do Estado, o relator Ricardo Fiuza foi acusado por alguns de seus pares progressistas de estar comprometido com os interesses das Forças Armadas. Em suas respostas, salientou que era parte da função de relator receber todos os interessados em opinar sobre o novo texto constitucional e que não via problema em fazê-lo em seu apartamento, fora dos registros públicos do Congresso.

Por mais que a carta de 1988 tenha buscado alargar sua concepção de direitos humanos, incluindo prerrogativas nos campos econômico, cultural e social, o arbítrio do regime de exceção se caracterizava de maneira mais evidente na constante violação de direitos civis fundamentais. Assim sendo, itens como inviolabilidade do domicílio e da correspondência, a proibição de prisões ilegais, o instituto do habeas-corpus, a garantia de ampla defesa aos acusados, a extinção de foros privilegiados ou tribunais especiais para julgamento de crimes de abuso de poder praticados por policiais e autoridades públicas, a par das clássicas liberdades de ir e vir, de associação, de opinião, de crenças político-ideológicas, bem como suspensão da censura à imprensa, a anistia aos condenados pela justiça militar e o retorno à vida civil dos clandestinos e exilados políticos formaram um conjunto básico de elementos a serem discutidos na constituinte como condicionantes para a passagem a um regime minimamente democrático.

Embora muitos destes pontos tenham sido contemplados no processo de formulação da carta de 1988, as instituições que formam o sistema de segurança pública - justiça, polícias e penitenciárias - foram pouco ou nada modificadas, o que representa obstáculo para a consecução dos direitos acima mencionados. Como lembrado anteriormente, essa continuidade não tem relação com a ausência de debates e propostas na sociedade civil acerca do tema, mas sim com a resistência de grupos políticos ligados à ordem antiga, que mantiveram seu poder de veto no período da transição para a democracia.

Do mesmo modo, esse exame (dos anais da constituinte) aponta a existência de poderosas forças conservadoras, comprometidas com os próceres da ditadura militar, que se opuseram com tenacidade à introdução de preceitos inspirados nos direitos humanos. Por exemplo, é possível flagrar esses constituintes valendo-se de argumentos como bons costumes e tradições cordatas da sociedade brasileira, o que dispensaria a inscrição de garantias no texto constitucional. Na mesma direção, foram presentes e atuantes os lobbies corporativos, principalmente relacionados às forças repressivas, com o propósito de manter intocável a organização das forças armadas e das polícias militares, grupos sequiosos de que mudanças institucionais pudessem representar perda de poder e - 0 mais temido - criar condições institucionais favoráveis para que denunciados por crimes contra os direitos humanos viessem a ser julgados por tribunais civis e, ao 
Pedro Benetti

final, condenados. (ADORNO, 2008, p. 201)

Na Constituição Federal de 1988, os direitos humanos aparecem no Título II Dos direitos e garantias fundamentais, que subdivide-se em cinco capítulos: (I) direitos e deveres individuais e coletivos; (II) direitos sociais; (III) direitos da nacionalidade; (IV) direitos políticos e (V) dos partidos políticos. Se mesmo os regimes autoritários preservaram o formalismo jurídico, relacionando em suas constituições algumas das clássicas garantias liberais aos cidadãos, no caso da carta de 1988 o rol de proteções contra o arbítrio do Estado aumentou significativamente.

Ao incorporar uma linguagem de proteção aos direitos humanos, consagrada internacionalmente em declarações e pactos, o Brasil buscava resolver uma hipoteca do período 1964-1985, mostrando ao mundo o compromisso com uma democracia ampliada e ao mesmo tempo garantindo à sua própria cidadania o afastamento do risco golpista e do retorno autoritário. Pretendia-se assim impor limites bem definidos à violência institucionalizada. O discurso construído a partir da ideia de segurança nacional é progressivamente abandonado no corpo da constituição em nome da defesa da cidadania.

Como ponto de partida, é necessário reconhecer que a Constituição de 1988 foi a primeira a definir o conceito de segurança pública como distinto do de segurança nacional, a partir do qual todas as demais Constituições brasileiras disciplinavam, de algum modo, as atividades de enfrentamento ao crime e a violência. Seu capítulo III, que trata do tema, é inédito no ordenamento constitucional brasileiro e, digno de destaque, sua redação sobrevive às 56 Emendas Constitucionais citadas. Porém, ainda em razão dos traumas do período autoritário, o tema era bastante indigesto, em especial para os intelectuais de esquerda, não assumindo relevância política e a conseqüente centralidade legislativa. A discussão sobre reformas nas polícias ficou para um segundo plano, talvez subsumida pela força da ênfase nas reformas macroeconômicas e das tensões e friç̧ões inerentes ao tema, que carecia de consensos mínimos em torno de modelos e parâmetros de trabalho. Dito de outra forma, a CF de 1988 avançou na construção de um novo conceito de segurança pública, mas, ao que tudo indica, apenas em oposição ao de segurança nacional, na tentativa instrumental de fornecer ao Estado condições e requisitos democráticos de acesso à justiça e garantia de direitos. Na prática, pouco alterou a estrutura normativa e burocrática responsável por mediar e solucionar conflitos.(Relatório de conexões metodológicas do Fórum Brasileiro de Segurança Pública, 2009, p. 5)

A defesa do Estado cede lugar à segurança pública, mecanismo de proteção do cidadão. Contudo, quando se analisa o Título V do texto constitucional de 1988, notase a continuidade de uma estrutura montada entre 1967 e 1969, no auge da repressão política. Para esse resultado concorreram pressões oriundas de diferentes setores, não apenas aqueles diretamente ligados à ditadura em queda. No curso da década de 1980 o aumento da criminalidade urbana ensejou o surgimento de políticos e articulistas que organizavam sua inserção no debate público a partir da crítica aos defensores dos direitos humanos. A resistência às políticas de humanização das prisões levadas adiante por Franco Montoro, na gestão 1982-1986 em São Paulo, foram exemplares do 
Pedro Benetti

tipo de resistência que se produziu aos que tentavam avançar políticas de controle sobre a atuação dos braços punitivos do Estado (DO RIO CALDEIRA, 2000; HIGA e ALVAREZ, 2019). Houve diferença significativa entre o clima de opinião que marcou as eleições estaduais de 1982 e o que circundou o pleito de 1986, quando governadores em importantes estados se elegeram com a plataforma de endurecimento das ações de combate à criminalidade urbana.Assim, o contexto no qual se deram as polêmicas constituintes contribuiu também para a preservação de uma estrutura que desconsiderou boa parte dos debates que se processaram na sociedade no decorrer da transição, que se ocuparam do esforço de conceber alternativas para o sistema de segurança pública e defesa do Estado herdados da ditadura.

\section{As alternativas propostas}

O momento de elaboração da Constituição foi marcado por diversos debates na sociedade brasileira, o que por vezes levou à produção de propostas apresentadas aos constituintes. Tais propostas chegaram aos constituintes de muitas maneiras, tanto sob a forma de sugestões registradas no parlamento por indivíduos ou organizações quanto por meio de documentos publicados, que embora não registrados na mesa diretora da Assembleia Nacional Constituinte pretendiam chamar a atenção dos deputados e senadores para a pertinência de suas colocações. Muitas dessas propostas foram pontuais, versando sobre algum artigo específico ou tópico que deveria ser tratado. Outras tiveram um recorte temático, embora não tenham se organizado como propostas globais na forma de um anteprojeto. Apresentamos aqui quatro iniciativas que discutiram o tema da segurança pública e defesa do Estado, elaboradas por atores coletivos, que buscaram dar conta destes temas de maneira sistemática. Deixamos de fora, portanto, sugestões pontuais encaminhadas à mesa da ANC e alternativas debatidas por convidados e parlamentares no próprio contexto da subcomissão IV-B (responsável pelo tema). Três delas foram anteprojetos de constituição elaborados respectivamente pela Comissão de Estudos Constitucionais formada pelo governo Sarney, a Comissão Afonso Arinos, pelo Partido dos Trabalhadores (PT) e pelo Partido da Frente Liberal (PFL). Tais anteprojetos apresentaram propostas globais de texto constitucional, que em algum momento versaram sobre os temas aqui analisados. Já a Comissão Teotônio Vilela foi formada anos antes e não teve como objetivo oferecer à sociedade uma proposta global de constituição, mas sim discutir caminhos para avançar uma agenda de direitos humanos em um momento no qual as graves violações estavam na ordem do dia. O resultado foi uma discussão mais ampla que, entretanto, apresenta diversas recomendações que dialogavam com os debates na constituinte.

\subsection{A Comissão Teotônio Vilela}

A Comissão Teotônio Vilela para os Direitos Humanos representa um bom exemplo de mobilização em torno da transformação das instituições do Estado responsáveis pelo combate à criminalidade. Constituída por parlamentares e outras figuras públicas em janeiro de 1983, a comissão trabalhou motivada pela discussão acerca de soluções para o sistema penitenciário brasileiro, o qual considerava em situação de colapso naquele momento. As intervenções produzidas pela comissão são exemplares dos principais temas colocados à época em relação ao debate sobre como abordar a temática da segurança pública na ordem nascente. A incorporação da gramática dos Direitos Humanos e a reversão da lógica da segurança nacional, em 
Pedro Benetti

nome de uma segurança pública enfocada na cidadania, eram pautas centrais nesse período de definição. Algumas das sugestões levantadas pela comissão, não incorporadas ao texto constitucional, são interessantes para pensar as possibilidades disponíveis à época dos debates constituintes, que tinham como objetivo a mudança nos padrões de relacionamento entre Estado e sociedade.

Naquele dia de maio de 1985, levamos ao presidente da república e ao seu ministro da justiça algumas propostas objetivas, entre as quais a introdução de algumas alterações no código penal, visando transformar as delegacias de polícia em juizado de instrução, passando a investigação a ser presidida por um juiz de direito; inclusão no código penal e na lei de imprensa, de dispositivos vedando a divulgação de nome ou nomes de suspeito ou suspeitos sem provas e antes da acusação formal; e declarando taxativamente que ninguém é culpado perante a lei antes de condenado. Quanto à polícia, sugeríamos a revisão dos critérios para a contratação de escrivães, reformulação dos cursos de formação de policiais, substituição da pressão psicológica e da tortura pela investigação científica nas delegacias de polícia. E mais, providencias para alterar as normas dos organismos competentes, a fim de que o suspeito detido possa avisar a família de que está detido e onde, possa conhecer a natureza da acusação, ter um advogado à sua disposição e não ser obrigado a prestar depoimento antes de ser aconselhado por um advogado. Quanto ao problema carcerário, sugeríamos: instalação imediata de detector de metais (semelhante ao dos aeroportos) na entrada dos presídios, para evitar a humilhante revista dos familiares dos detentos, instalação de mecanismos mais modernos (com auxílio de computador central) capazes de determinar o dia exato em que a pena do detento termina. (Comissão Teotônio Vilela, 1986, p. 67)

A década de 1980 é palco de dois fenômenos que tem profundo impacto nos debates sobre segurança pública. Por um lado, a abertura política permite que os relatos de tortura e execução de presos políticos durante o período autoritário comecem a circular mais livremente pelo país. Por outro lado, a criminalidade urbana assistiu uma escalada sem precedentes, que tinha muitos elementos em sua base. A severa crise econômica que assolava o Brasil, o rápido processo de urbanização - sem que as estruturas das grandes cidades pudessem oferecer níveis adequados de vida para os migrantes - e a crescente organização das redes responsáveis pela distribuição e comercialização de entorpecentes são elementos que compõem esse quadro de aumento da violência urbana. Nesse contexto, observa-se uma dinâmica de disputa entre a crescente valorização dos direitos humanos como eixo de organização do Estado e o reforço da lógica de combate à criminalidade a partir do confronto, numa atualização da doutrina de segurança nacional que mantinha a lógica da guerra substituindo os comunistas pelos traficantes como inimigos do Estado e da sociedade. Essa tensão entre proteção aos direitos humanos e "guerra" ao crime é constitutiva da institucionalidade que nasceria (ou se preservaria) no campo da segurança pública, que pode ser compreendida, resumidamente, como o sistema formado pelas polícias, pelo judiciário e pelas instituições de encarceramento. 
Pedro Benetti

judiciário e um sistema penitenciário como departamentos estanques. Para bem funcionar, eles têm de ser considerados como um todo, dentro de um trabalho integrado, considerados como um todo, dentro de um trabalho integrado. Como integrar os três organismos, para que tenhamos policiamento que de segurança ao povo, uma Justiça que atenda às necessidades desse mesmo povo e um sistema carcerário voltado para a regeneração? (Comissão Teotônio Vilela, 1986, p. 74)

Nesse período, a discussão sobre segurança pública confundia-se com a própria discussão sobre democracia, na medida em que se buscava compreender quais eram os limites que deveria ter o Estado no emprego da força e na manutenção da ordem. $O$ desafio passava pelo exercício da autoridade de maneira não autoritária. A tensão mencionada no parágrafo anterior entre uma abordagem da segurança pública cujo enfoque recai sobre a "guerra ao crime" e uma outra que se centra na superação das violações aos direitos humanos pode ser encontrada também nos debates da constituinte. Nessa ocasião, os parlamentares do bloco conservador atentam para a necessidade de demarcar uma fronteira entre os "cidadãos de bem" e os "bandidos", que devem receber firmes respostas das instituições de segurança. Uma lógica que se aprofundaria com o tempo. De certa forma, ao pensar sobre o braço armado do Estado, pensava-se no centro da disputa entre as forças sociais e políticas que se mobilizaram a partir da segunda metade da década de 1970 para pôr fim ao autoritarismo e aquelas forças que reconheciam na ditadura um mal necessário, que cometeu excessos, mas que não podia ser descartada como um todo na construção da nova ordem.

A relação efetiva que existe entre regime político e
número de mortos pelo aparelho de Estado: quanto mais
consolidado o Estado de Direito, menos mortes, quanto
mais autoritário o regime e menor o controle da
sociedade sobre o aparelho policial, mais mortos,
independentemente da variável demográfica ou dos
índices de criminalidade. (Comissão Teotônio Vilela, 1986,
p. 141)

A comissão Teotônio Vilela é representativa dos debates transcorridos nesse momento histórico pela relação que construía entre o aparelho repressivo responsável pela consecução da repressão política e as mudanças necessárias para a construção de um regime democrático. Ainda que tenha encerrado seus trabalhos antes da Assembleia Nacional Constituinte, a Comissão Teotônio Vilela ofereceu diversas sugestões sobre como organizar um sistema de segurança pública compatível com a defesa dos direitos humanos. Tais sugestões tinham como pressuposto a superação da arquitetura institucional herdada do período anterior.

\subsection{A Comissão Afonso Arinos}

Diferentemente da Comissão Teotônio Vilela, a Comissão Provisória de Estudos Constitucionais, conhecida como Comissão Afonso Arinos, se reuniu com o objetivo de preparar um anteprojeto para a carta constitucional que viria. Ela foi formada por meio do decreto $n^{\circ}$ 91.450, de 18 de julho de 1985 e teve entre seus membros personalidades como Gilberto Freyre, Celso Furtado, Candido Mendes, Hélio Jaguaribe, Miguel Reale entre outros ${ }^{11}$. Assim como a Comissão Teotônio Vilela, a Afonso Arinos traduziu o momento de preocupação com a criação de mecanismos institucionais que pudessem frear o uso arbitrário de violência por parte do Estado. O conteúdo do 
Pedro Benetti

anteprojeto reflete a preocupação de salvaguardar os cidadãos e a sociedade das violações recorrentes do período anterior.

As questões relativas à organização da segurança pública e aos mecanismos de defesa do Estado estão concentradas, sobretudo, no título VII do anteprojeto: Da defesa do Estado, da sociedade civil, das instituições democráticas. No primeiro capítulo deste título, sobre as Forças Armadas, o anteprojeto define que apenas por meio de iniciativa expressa dos poderes constitucionais os militares podem ser chamados a garantir a ordem interna. Já o capítulo II organiza a estrutura da segurança pública, estabelecendo polícias civis e estaduais, permitindo a formação de polícias militares por iniciativa dos estados apenas nos casos em que houvesse necessidade de complementar os esforços de policiamento ostensivo.

Art. 416 - Compete aos Estados a preservação da ordem pública, da incolumidade das pessoas e do patrimônio, através da polícia civil, subordinada ao Poder Executivo. § $1^{0}$ - A polícia civil, além da função de vigilância ostensiva e preventiva que the competir, será incumbida da investigação criminal. § $2^{\circ}-$ A polícia civil poderá manter quadros de agentes uniformizados.

Art. 417 - Os Estados poderão manter polícia militar, subordinada ao Poder Executivo, para garantia da tranquilidade pública, por meio de policiamento ostensivo, quando insuficientes os agentes uniformizados da polícia civil e do Corpo de Bombeiros.

Art. 418 - Observados os princípios estabelecidos neste Capitulo, os Estados organizarão a sua atividade policial, de modo a garantir a segurança pública, utilizando os seus efetivos e equipamentos civis e militares.

Tal estrutura apontava para um policiamento de ciclo único, no qual a mesma instituição se encarregaria das atividades de prevenção, repressão e polícia judiciária. O texto se preocupou ainda com a determinação das atribuições da polícia federal, além de reservar aos municípios com mais de 200 mil habitantes a prerrogativa de constituir guarda municipal. O último artigo deste capítulo revela a já mencionada inquietação em relação aos abusos de poder que marcaram a ditadura militar.

Art. 422 - Toda a atividade policial será organizada segundo os princípios da hierarquia e da disciplina e exercida com estrita observância da lei, que punirá qualquer abuso de autoridade.

Cabe destacar que o anteprojeto formulado pela Comissão Afonso Arinos eliminou qualquer referência à segurança nacional do texto constitucional, extinguindo, assim, o Conselho de Segurança Nacional, substituído por um Conselho de Defesa Nacional, bastante mais enxuto e composto apenas por alguns dos ministros do poder executivo federal. Os mecanismos de defesa do Estado estipulados pela comissão foram os estados de alarme e sítio. O primeiro foi concebido para situações cuja gravidade não requeira a decretação do estado de sítio. Sua decretação é de competência do presidente, ouvido o Conselho de Defesa Nacional, e sua instalação implica a restrição de algumas liberdades individuais e coletivas. Não obstante, o texto esclarece que a incomunicabilidade de presos está vedada e as prisões por crimes contra o Estado devem ser comunicadas imediatamente a um juiz, não podendo superar os dez dias de duração. Já o estado de sítio só pode ser decretado pelo Congresso Nacional, ainda que o presidente possa ter a iniciativa de solicitá-lo. Embora 
Pedro Benetti

mais restritivo do que o estado de alerta, o capítulo sobre o estado de sítio ressalva:

Art. 434 - Expirado o estado de sítio, cessarão os seus
efeitos, sem prejuízo das responsabilidades pelos abusos
cometidos. Parágrafo único - As medidas aplicadas na
vigência do estado de sítio serão, logo que ele termine,
relatadas pelo Presidente da República, em mensagem ao
Congresso Nacional, com especificação e justificação das
providências adotadas, indicando nominalmente os
atingidos e as restrições aplicadas.
Art. 435 - A inobservância de qualquer das prescrições do
presente Capítulo e do Capítulo anterior tornará ilegal a
coação e permitirá aos prejudicados recorrer ao órgão
competente do Poder Judiciário, que não poderá escusar-
se de conhecer do mérito dos pedidos, quando forem
invocados direitos e garantias assegurados nesta
Constituição.

O anteprojeto formulado pela Comissão Afonso Arinos desagradou o presidente Sarney, que o encomendara. Dessa forma, ele sequer foi enviado à Assembleia Nacional Constituinte para que servisse como norte para os trabalhos que lá se desenrolariam. No que tange especificamente às discussões sobre defesa e segurança do Estado e da sociedade civil, as propostas apresentadas pela comissão foram desconsideradas já nos primeiros debates, embora defendidas por alguns dos convidados ouvidos nas audiências públicas da constituinte.

\subsection{O anteprojeto do PT}

Enquanto as comissões Teotônio Vilela e Afonso Arinos foram formadas por iniciativa dos poderes públicos constituídos - Congresso no primeiro caso e presidência da república, no último - o anteprojeto de constituição apresentado pelo Partido dos Trabalhadores foi resultado de um acúmulo organizado por um ator político que não tinha sua autoridade fundada nestes espaços de poder. No segundo semestre de 1985, a direção nacional do PT solicitou ao jurista Fabio Konder Comparato a redação de uma proposta de constituição, que foi entregue em fevereiro de 1986. O partido, que elegeu dezesseis deputados nas eleições de 15 de novembro de 1986, defendeu sempre a ideia de uma constituinte exclusiva, que fosse eleita apenas para essa tarefa e não confundisse seus trabalhos com a atividade parlamentar. Os caminhos para a ruptura com a ordem anterior, apresentados pelo PT em seu anteprojeto, passam pela extinção da justiça militar, supressão de qualquer menção à segurança nacional no texto constitucional e possibilidade de revisão judicial dos atos institucionais e ditos revolucionários do regime militar (COMPARATO, 1986).

No que tange aos mecanismos de defesa do Estado e da sociedade, 0 anteprojeto do PT busca limitar as condições nas quais o poder público pode recorrer a medidas de exceção em nome da manutenção da ordem. Ele suprime o estado de emergência e as medidas de emergência existentes anteriormente e estabelece apenas o estado de sitio como caso em que se tolera a suspensão de algumas liberdades fundamentais. Ainda assim, as condições para a decretação do sítio eram bastante restritas, prevendo, por exemplo, que após a sua suspensão o Congresso poderia votar pela desaprovação da medida e responsabilizar o presidente através de processo de impeachment (COMPARATO, 1986, p. 39). Já em relação às forças armadas e forças policiais, o anteprojeto "rompe decididamente com a péssima tradição inaugurada em 1891, consistente em atribuir na Constituição às forças militares o encargo de defender as instituições públicas, como se elas fossem uma espécie de poder moderador 
Pedro Benetti

fardado." (COMPARATO, 1986, p. 52). Para tanto, o texto estabelece expressamente o comando do presidente e seus ministros sobre as forças armadas, além de determinar sua atuação voltada exclusivamente para conflitos externos. No âmbito interno, a responsabilidade sobre a manutenção da ordem seria de exclusividade das instituições policiais, que seriam desmilitarizadas e responderiam aos governadores estaduais.

\begin{abstract}
Art. 189 - A Polícia federal e as Polícias estaduais, incumbidas de garantir a segurança pública e de colaborar com o Poder Judiciário e com o Ministério Público na apuração das infrações criminais, são órgãos de natureza civil, não podendo, em hipótese alguma e de nenhuma forma, submeter-se à autoridade militar.
\end{abstract}

O anteprojeto de constituição apresentado pelo PT não revela qualquer tipo de compromisso com a ordem anterior, buscando refundar todo o sistema político e a ordem social a partir de uma lógica de limitação do poder e do uso da força. Curiosamente, o parlamentar petista que ocupa a titularidade da subcomissão de defesa do estado, da sociedade e de sua segurança, José Genoíno, não acompanha o acúmulo reunido pelo próprio partido em seu anteprojeto, defendendo, por exemplo, a continuidade das polícias militares como responsáveis pelo policiamento ostensivo no país ${ }^{12}$.

\title{
3.4 O anteprojeto do PFL
}

Ao contrário das demais propostas aqui resumidas, o anteprojeto de constituição apresentado pelo Partido da Frente Liberal é o que revela um elo de ligação claro com o regime que se queria superar. Apresentado já no curso da constituinte de $1987-8^{13}$, o anteprojeto do PFL coincidiu, em muitos pontos, com o texto apresentado pelo relator Ricardo Fiúza, membro do partido, como resultado dos trabalhos na Subcomissão de defesa do estado, da sociedade e sua segurança.

O partido se formara no ano de 1985 após uma parcela do Partido Democrático Social (PDS) - herdeiro da Aliança Renovadora Nacional (ARENA) - dissentir dos rumos adotados pelo partido nas discussões sobre as eleições indiretas daquele ano, que escolheram Tancredo Neves como primeiro presidente civil do país em 21 anos. Assim sendo, a maior parte dos políticos do PFL tiveram profunda relação com o regime militar e percebiam a forma de organização do Estado por ele legada como algo a ser preservado, pelo menos parcialmente.

Assim sendo, o partido defendeu a continuidade das justiças militares, federal e estaduais, como foro apropriado para o julgamento de crimes militares, dos militares e pessoas assemelhadas. No que diz respeito à defesa do Estado, a proposta do partido manteve o estado de sítio como uma prerrogativa do presidente, além de estabelecer a possibilidade de intervenção federal em caso de graves perturbações da ordem pública. Por fim, o partido defendeu também que o papel das forças armadas inclua a "a garantia dos poderes constituídos, da lei, da ordem e de Soberania Nacional". As propostas apresentadas pelo PFL não representavam mudanças significativas em relação ao texto constitucional de 1967. Das quatro alternativas discutidas aqui como representativas dos debates que se processavam em torno do tema da segurança na constituinte, esta é a única que se coloca claramente em linha de continuidade com o passado imediato, representando também uma defesa de interesses corporativos das instituições militares. É essa também a proposta que mais se assemelha ao texto que sairia da subcomissão responsável por pensar esse tema da segurança do Estado e da sociedade, ainda que este texto viesse a sofrer alterações significativas nas comissões 
Pedro Benetti

seguintes e na versão final da Constituição.

\section{Conclusão}

A inspiração benjaminiana de uma história feita a contrapelo, em busca das ruínas e derrotas de quem disputou um futuro mais justo, encontra, nesse caso, o mesmo sentido de abertura identificado acima como marca dos anos 1980. Em outras palavras, trata-se de uma volta ao passado que lança luz sobre o presente, abrindo-o para novas disputas, renovando as energias e ferramentas dos atores que hoje questionam o legado autoritário e a forma de organização das forças repressivas do Estado.

O objetivo deste texto, portanto, não passou pela recuperação dos debates que efetivamente conformaram as instituições armadas do Estado tal como a conhecemos, mas sim pela sistematização de algumas alternativas apresentadas naquele momento e hoje esquecidas ${ }^{14}$. Ao observarmos os registros das discussões no âmbito da própria constituinte, percebemos uma série de expedientes dedicados a neutralização destas alternativas, desde a composição da subcomissão responsável pelo tema, cuja relatoria e presidência couberam a políticos conservadores, até o emprego de uma série de argumentos que afastaram pouco a pouco os impulsos renovadores. A lista de convidados a falar naquele espaço, composta majoritariamente de integrantes das forças armadas do Estado, também foi importante para amadurecer a noção de que tais temas não deveriam ser objeto de discussão da sociedade civil. Mesmo quando um destes apresentava alguma proposta reformadora, como a desmilitarização das polícias, os membros da comissão rejeitavam a ideia com base no argumento da tradição, reiterando que experiências de outros países não podiam servir como norte para a organização do Estado brasileiro. Assim, por meio de estratégias parlamentares combinadas, as forças defensoras do modelo implementado pela ditadura militar fizeram prevalecer sua perspectiva de organização do Estado, pelo menos no que tange às forças repressivas.

Tal perspectiva resumia, em alguma medida, boa parte da tensão que atravessou os debates constituintes acerca da extensão do controle civil sobre o poder das corporações armadas. Não à toa as discussões sobre Forças Armadas, polícias, estado de sítio e outros estados emergenciais foram realizadas em conjunto. Por mais que possam parecer aspectos muito diferentes da realidade, todas dizem respeito a este nervo sensível do processo de transição. Se o regime anterior se caracterizara pela significativa ampliação do poder militar sobre as mais diversas esferas da vida pública, tratava-se agora de recuperar o poder civil sobre agendas especificas (estatais, educação, saúde etc) bem como de estabelecer mecanismos externos de controle civil sobre os braços armados do Estado. Em outras palavras, era preciso não apenas que os militares se recolhessem à caserna, mas que o próprio desempenho de suas atividades fosse objeto de permanente vigilância. Não obstante, como mencionado acima, o processo de transição não se deu sobre as ruínas do regime anterior, mas em constante negociação com os incumbentes da antiga ordem. Isso significa que a extensão do controle civil sobre o uso de violência por parte das instituições armadas do Estado foi sempre disputada e, no caso específico aqui analisado, limitado pela preservação de uma estrutura em muitos aspectos semelhante à anterior.

Nesse sentido, embora focado no processo histórico, o texto dialoga com a atualidade, na medida em que trata de temas ainda sensíveis ao nosso debate público. Para além de temas que ganharam maior notoriedade, como a desmilitarização das forças policiais, aparecem também outros pontos que seguem pertinentes diante da 
A CONSTITUIÇÃO QUE NÃO FOI: PROJETOS DERROTADOS PARA A

REVISTA ESTUDOS POLÍTICOS Vol. $11 \mid$ N.22 ISSN 2177-2851 SEGURANÇA PÚBLICA NA NOVA REPÚBLICA

Pedro Benetti

situação de graves e permanentes violações aos Direitos Humanos mais básicos nos sistemas de segurança pública e punição do país. Destaca-se, por exemplo, a sugestão da Comissão Teotônio Vilela de informatização do controle de cumprimento de penas por parte dos detentos. Assusta pensar que mais de três décadas depois, com expressivo avanço das ferramentas tecnológicas, as prisões brasileiras sigam acumulando pessoas com penas cumpridas, à espera de alvarás de soltura.

Por fim, a recente experiência de ocupação militar dos altos escalões do poder executivo reabre o debate sobe o "papel moderador dos militares", tal como citado no anteprojeto do PT. A derrota das perspectivas que buscavam ampliar o controle sobre a atuação dos militares, principalmente no âmbito interno, abriu margem para que diversas vezes fossem empregadas as Forças Armadas em operações de garantia da lei e da ordem, pelo menos desde 1992. A presença dos militares como fiadores da ordem consta dentre as muitas razões para a emergência do bloco de poder que hoje governa o país e ameaça dia após dia as instituições organizadas pela Carta de 1988.

(Recebido para publicação em setembro de 2020)

(Reapresentado em setembro de 2020)

(Aprovado para publicação em dezembro de 2020)

\section{Cite este artigo}

BENETTI, Pedro, 2020. A constituição que não foi: projetos derrotados para a segurança pública na Nova República. Revista Estudos Políticos: a publicação semestral do Laboratório de Estudos Hum(e)anos (UFF). Rio de Janeiro, Vol.11 | N.22, pp.35-57, dezembro de 2020.

\section{Notas}

1. Ver, por exemplo:

https://brasil.elpais.com/brasil/2019/02/21/opinion/1 550780431_587980.html e https://www.dw.com/ptbr/a-lei-da-anistia-e-o-esquecimento-dos-crimes-daditadura-militar/a-45082182 acessados em $12 / 01 / 2021$

2. No Brasil e na América Latina um campo de estudos que se convencionou denominar como Justiça de Transição tem ganhado cada vez mais pesquisadores e trabalhos, como evidencia a relativamente recente formação da Rede LatinoAmericana de Justiça de Transição (http://rlajt.com/ ), dentre outras iniciativas. Este campo, dominado por acadêmicos do direito, inclui também historiadores, politólogos, psicanalistas e outros profissionais na grande área das humanidades. Mas para além deste campo, filósofos, sociólogos e 
Pedro Benetti

historiadores têm desenvolvido em seus respectivos campos diversos trabalhos que pretendem construir relações entre nosso presente violento e o imediato passado autoritário. Os aniversários do golpe militar de 1964 têm sido particularmente marcados por publicações que fazem o balanço dessas continuidades, como "Ecos do Golpe" (2014), "O que resta da ditadura" (2010), dossiês em periódicos, dentre outras manifestações.

3. Comunidade de informações era a forma pela qual se designavam os setores das forças armadas do Estado dedicados à repressão política. Inclui estruturas como o SNI, CODI-DOI, DOPS dentre outras.

4. Some-se a esses elementos o aumento das pressões internacionais sobre o regime brasileiro, fruto de mudanças geopolíticas e campanhas de opinião conduzidas por brasileiros exilados e comitês de solidariedade.

5. Na Chacina da Lapa foram assassinadas algumas das principais lideranças do PCdoB que sobreviveram à Guerrilha do Araguaia, como Ângelo Arroyo.

6. Para uma perspectiva da Operação Radar, que durante muito tempo foi desconhecida do público brasileiro, vale observar os perfis de desaparecidos presentes no volume III do relatório final da Comissão Nacional da Verdade (2014). A documentação presente no Arquivo Nacional revela que a desaparição de pelo menos 8 lideranças do PCB era parte de uma operação que buscava desarticular o partido e evitar que num eventual retorno à democracia políticos experientes do período 1946-1964 pudessem rearticular um projeto de esquerda no país. Alguns dos nomes de destaque que desapareceram durante a operação foram David Capistrano, João Massena, Orlando Bonfim, Elson Costa, Hiram de Lima Pereira, Jaime Amorim de Miranda, José Montenegro entre outros.

7. BRASIL. Emenda Constitucional no 26 de 27 de novembro de 1985. Convoca Assembleia Nacional Constituinte e dá outras providências. Disponível em: http://www.planalto.gov.br/cciVil 03/Constituicao/Em endas/Emc anterior1988/emc26-85.htm. Acesso em 24 de nov. 2016.

8. A afirmação de Ulysses teria sido feita em resposta a uma sugestão do então secretário de segurança pública do Estado de São Paulo que, identificando patamares elevados de violência por parte de sua 
Pedro Benetti

Polícia Militar, sugeriu que o novo texto constitucional mudasse o sistema de polícias vigente.

9. O lobby teria incluído reuniões, visitas de parlamentares a instalações militares dentre outros mecanismos.

10. Trata-se da subcomissão IV-B Subcomissão de Defesa do Estado, da Sociedade e de sua Segurança

11. A íntegra do anteprojeto e os nomes que compuseram a comissão estão disponíveis em http://www.senado.leg.br/publicacoes/anais/constitui nte/AfonsoArinos.pdf Acessado em 11/12/2016

12. $\mathrm{O}$ que pode ser observado na leitura dos anais da Subcomissão IV-B

13. O projeto foi apresentado em maio de 1987. Ver http://www2.senado.leg.br/bdsf/item/id/130943

14. Analisei os debates da Subcomissão IV-B em minha tese de doutorado, defendida em 2017.

\section{Referências bibliográficas}

ADORNO, Sergio. Direitos Humanos. In OLIVEN, Ruben George [et al]. A Constituição de 1988 na vida brasileira, pp.191-224, Aderaldo \& Rothschild Editores Anpocs, São Paulo 2008.

BATISTA, Vera Malaguti. Direitos (e) Humanos no Brasil Contemporâneo. Jura Gentium, v. 1, 2008.

Estado de polícia. In KUCINSKI, Bernardo [et al]. Bala perdida: a violência policial no Brasil e os desafios para sua superação. São Paulo: Boitempo Editorial, 2015.

CAMARGO, Aspásia; DINIZ, Eli. Continuidade e mudança no Brasil da Nova República. São Paulo: Vértice; Editora Revista dos Tribunais, 1989.

CARVALHO, Alessandra. Características da transição no Brasil, In LINHARES, Maria Yedda Leite (Org). História geral do Brasil. Rio de Janeiro: Editora Campus, 2000.

CASTRO, Celso; D'ARAUJO, Maria Celina; SOARES, Gláucio Ary Dillon. Os anos de chumbo: a memória militar sobre a repressão, Rio de Janeiro: RelumeDumará, 1994.

A volta aos quartéis: a memória militar sobre a abertura. Rio de Janeiro: Relume- 
Pedro Benetti

Dumará, 1995.

COMISSÃO TEOTÔNIO VILELA. Democracia $x$ violência: reflexões para a Constituinte. Paz e Terra, 1986.

COMPARATO, Fábio Konder. Muda Brasil!: Uma constituição para o desenvolvimento democrático. Brasiliense, 1986.

DO RIO CALDEIRA, Teresa Pires. Cidade de muros: crime, segregação e cidadania em São Paulo. Editora $34,2000$.

DINIZ, Eli; BOSCHI, Renato Raul; LESSA, Renato. Modernização e consolidação democrática no Brasil: dilemas da Nova República. Rio de Janeiro: Editora Vértice, 1989.

FERNANDES, Florestan. Que tipo de República? São Paulo: Editora Brasiliense, 1986.

FICO, Carlos. Como eles agiam: os subterrâneos da Ditadura Militar: espionagem e polícia política. Rio de Janeiro: Editora Record, 2001.

FÓRUM BRASILEIRO DE SEGURANÇA PÚBLICA, Mapeamento das conexões metodológicas da produção acadêmica brasileira em torno dos temas da violência e da segurança pública e as suas relações com as políticas públicas da área adotadas nas duas últimas décadas (1990-2000). Disponível em www.forumseguranca.org.br, 2009. Acessado em 12/12/2016.

HIGA, Gustavo Lucas; ALVAREZ, Marcos César. Humanização das prisões e pânicos morais: notas sobre as "Serpentes Negras". Estudos Avançados, v. 33, n. 96, p. 69-90, 2019.

IASI, Mauro Luis; COUTINHO, Eduardo Granja (Orgs.). Ecos do golpe: a persistência da ditadura 50 anos depois. Rio de Janeiro: Mórula, 2014.

KARAM, Maria Lucia. Violência, militarização e 'guerra às drogas'. In KUCINSKI, Bernardo [et al]. Bala perdida: a violência policial no Brasil e os desafios para sua superação. São Paulo: Boitempo Editorial, 2015.

KUCINSKI, Bernardo. Jornalistas e revolucionários: nos tempos da imprensa alternativa. Editora Página Aberta: São Paulo,1991.

LESSA, Renato. In DINIZ, Eli; BOSCHI, Renato Raul; LESSA, Renato. Modernização e consolidação democrática no Brasil: dilemas da Nova República. São Paulo: Editora Vértice, 1989. 
Pedro Benetti

O'DONNELL, Guillermo; SCHMITTER, Philippe C. Transições do regime autoritário: primeiras conclusões. São Paulo: Vértice, 1988.

PÉCAUT, Daniel. Os intelectuais e a política no Brasil: entre o povo e a nação. São Paulo: Editora Ática, 1990.

PERUSSO, Marco de Antonio. Em busca do "novo": intelectuais brasileiros e movimentos populares nos anos 1970/1980. São Paulo: Annablume, 2009.

PILATTI, Adriano. A Constituinte de 1987-1988: progressistas, conservadores, ordem econômica e regras do jogo. Rio de Janeiro: Lúmen Júris, 2008.

PINHEIRO, Paulo Sérgio. Continuidade autoritária e construção da democracia: Relatório final, Sâo Paulo: NEV-USP, 1999.

SAFATLE, Vladimir. Do uso da violência contra o estado ilegal. In: TELES, Edson; SAFATLE, Vladimir (Orgs.) O que resta da ditadura. São Paulo: Boitempo Editorial, 2010.

SOARES, Luiz Eduardo. Por que tem sido tão difícil mudar as polícias? . In KUCINSKI, Bernardo [et al]. Bala perdida: a violência policial no Brasil e os desafios para sua superação. São Paulo: Boitempo Editorial, 2015.

TEIXEIRA DA SILVA, Francisco Carlos. A Modernização Autoritária: Do golpe militar à redemocratização 1964/1984, In LINHARES, Maria Yedda Leite (Org). História geral do Brasil. Rio de Janeiro: Editora Campus, 2000.

VIANNA, Luiz Werneck. Caminhos e Descaminhos da Revolução Passiva à Brasileira. Dados [online]. 1996, vol.39, n.3, pp. http://dx.doi.org/10.1590/S001152581996000300004.

Travessia: da abertura à constituinte.

Rio de Janeiro: Livraria Taurus Editora, 1986.

ZAVERUCHA, Jorge. Relações civil-militares: o legado autoritário da constituição brasileira de 1988. In: TELES, Edson; SAFATLE, Vladimir (Orgs.) O que resta da ditadura. São Paulo: Boitempo Editorial, 2010. 